\title{
Aesthetic Surgery of the Female Genitalia
}

\author{
Julie M.L.C.L. Dobbeleir, M.D., ${ }^{1}$ Koenraad Van Landuyt, M.D., Ph.D., ${ }^{2}$ \\ and Stan J. Monstrey, M.D., Ph.D.2
}

Aesthetic genital surgery seems to have become a fashionable issue nowadays. Many procedures and techniques have been described these last years, but very few longterm results or follow up studies are available. The novelty of this aspect of plastic surgery and the lack of evidence-based interventions, have led to a comparison with female genital mutilation. In this article, the authors provide an overview of the possible surgical procedures as well as the general principles of aesthetic surgery of the female genitalia.

KEYWORDS: Genital surgery, genital cutting, labioplasty, vaginal tightening

Aesthetic surgery of the female genitalia is a much discussed topic in the popular press as well as the scientific journals. It seems to be fashionable for men and women of today's world to have their genitals altered.

Although it might strike as a new trend quickly arising in all layers of society, it has been around for ages. The genital ideal may differ historically and crossculturally, yet in every society, social and cultural customs, often supported by medical rationale and health explanations, seem to justify the need for particular female genitalia.

Aesthetic female genital surgery involves surgery on normal female external genitalia; therefore, it falls into the same category as liposuction, breast augmentation, facial rejuvenation, cosmetic dental surgery, or any other aesthetic surgery procedure to the body.

It is designed to improve the appearance subjectively, and potentially provide psychological and functional improvement in sexual stimulation and satisfaction. ${ }^{1}$

Ever since aesthetic genital surgery became a more common part of the plastic surgeon's armamenta- rium, many questions have been raised, regarding technical issues, indications, and-not in the least-ethics, but few scientific answers are available.

As for every new specialty, guidelines need to be set up and long-term studies are a necessity. Complicating the issue even more is the fact that genital beauty is very culturally defined. The same template and indications cannot be used cross-culturally.

For example, in Japan the so-called winged butterfly appearance (Fig. 1) of the smaller labia is greatly admired and considered sexually desirable. In Western society, protruding inner labia are considered less attractive, whereas in parts of Africa, the inner labia are deliberately stretched from a young age. The ritual is known as Kudenga and is believed to optimize sexual intercourse. ${ }^{2,3}$

\section{ANATOMY AND PHYSIOLOGY}

Before understanding aesthetic genital surgery, one needs to have a thorough knowledge of the anatomy and the normal physiological changes occurring within the anatomy.
${ }^{1}$ Department of General Surgery, University Hospital Leuven, Leuven, Belgium; ${ }^{2}$ Department of Plastic Surgery, University Hospital Gent, Gent, Belgium.

Address for correspondence and reprint requests: Stan J. Monstrey, M.D., Ph.D., Department of Plastic Surgery, University Hospital Gent, De Pintelaan 185, 2K12C, B-9000 Gent, Belgium (e-mail: Stan.Monstrey@UGent.be).

Aesthetic and Functional Genital and Perineal Surgery: Female;
Guest Editors, Christopher J. Salgado, M.D., and Stan J. Monstrey, M.D., Ph.D.

Semin Plast Surg 2011;25:130-141. Copyright (C) 2011 by Thieme Medical Publishers, Inc., 333 Seventh Avenue, New York, NY 10001, USA. Tel: +1(212) 584-4662.

DOI: http://dx.doi.org/10.1055/s-0031-1281482.

ISSN 1535-2188. 


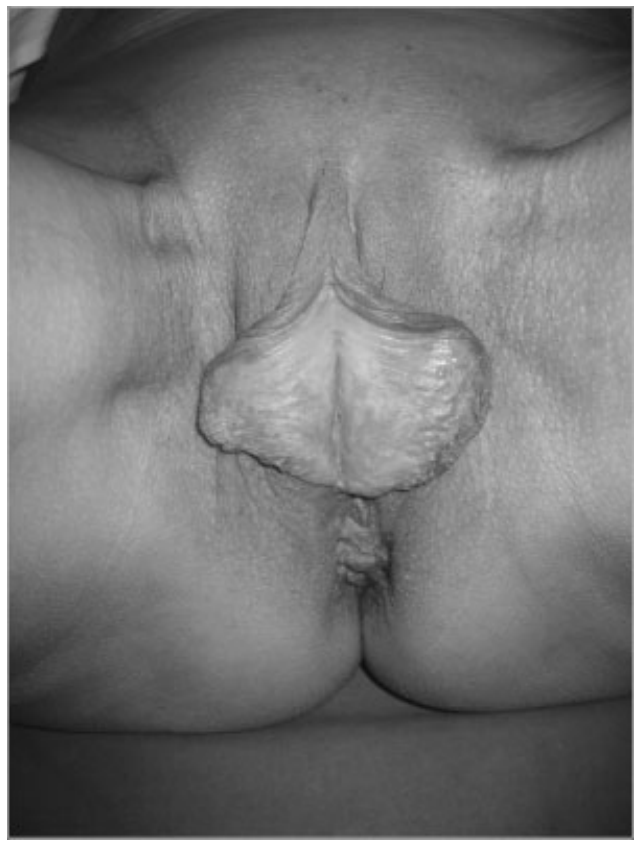

Figure 1 Winged butterfly appearance.

It is here that the first problem arises: What should we consider as normal vulvovaginal anatomy?

Female genital anatomy was first described in 1899 by Waldeyer who reported that normotrophic labia minora measure 2.5 to $3.5 \mathrm{~cm} .{ }^{4}$ In a more recent study, Lloyd et al extensively measured the external and internal female genitalia and also studied color changes and texture, thereby mapping the female genitalia in a whole new way. ${ }^{5}$ Their study found that there is a much larger variation than first assumed: They reported a mean (labia minora) width of $2 \mathrm{~cm}$, but found a natural variation between $7 \mathrm{~mm}$ and $5 \mathrm{~cm}^{5}$

It cannot be denied that as women age, physiologic changes in their genital area occur. Because procreation is often seen as the primary function of female genitalia, it is only natural that they are at their best during fertile age.

In an aging vagina, there is loss of tone and tightness due to slackness in the pelvic floor and of vaginal muscles after childbirth. This might result in a feeling of wideness and less sexual sensitivity for both women and their partners. The mons pubis progressively enlarges through fat deposits and sagging. In contrast to the mons pubis, there is volume loss in the labia majora, increasing the optical sagging even more.

With growing age hypertrophy of the labia minora occurs, although this is not the only cause of hypertrophy. Labia minora hypertrophy can also be secondary to mechanical irritation by intercourse or masturbation, childbirth, lymph statis, myelodysplastic disease, chronic irritation from dermatitis or urinary incontinence. It is multifactorially defined, meaning that also hereditary factors play a certain role. The importance of genetics versus environmental influences has not yet been elucidated.

\section{GENERAL PRINCIPLES}

The absence of guidelines and evidence about aesthetic genital surgery has led to a comparison with female genital mutilation. In most Western nations, irrelevant of age, ethnic background, and consent, female genital mutilation or cutting is illegal. ${ }^{8-10}$

The World Health Organization refers to female genital cutting as

"all procedures involving partial or total removal of the external female genitalia or other injury to the female genital organs whether for cultural, religious or non-therapeutic reasons."

Unfortunately, this definition does not distinguish the traditional practice of female genital cutting from elective vaginovulvar plastic surgery, thus giving rise to controversy. ${ }^{11}$

Female genital cutting originated in Arabic countries as early as $450 \mathrm{BC}$. Although in some Arabic countries, such as Sudan, the ritual is closely connected with the Islamic religion; female genital cutting actually predates Islam and is not condoned by that religion because Islam forbids any harm inflicted on God's creation. $^{10,12}$

Even in the United States and Great Britain from the early 1800 s to the mid-1950s clitoridectomy and hysterectomy were believed to treat diverse disorders such as masturbation, lesbianism, hysteria, debility, nymphomania, etc. Sigmund Freud once opined that "elimination of clitoral sexuality is a necessary precondition for the development of femininity, since it is immature and masculine in its nature." ${ }^{, 12}$

In Arabic culture, female genital cutting is called Khafd (reduction) or Tahara (purification). Its purpose is to remove all male qualities so that a woman is fit for marriage. $^{13,14}$

According to the WHO, there are four types of female genital cutting:

- Type 1: excision of prepuce with/without excision part/all clitoris

- Type 2: excision of clitoris with partial/total excision labia minora

- Type 3: excision of part/all external genitalia and narrowing vaginal opening (infibulation)

- Type 4: piercing, incising or stretching clitoris and/or labia, cauterization by burning of the clitoris and surrounding tissue

Immediate complications of female genital cutting include severe pain, cellulitis, sepsis, urinary 
retention, hemorrhage, shock, and even death. Longterm complications include cysts, abscesses, keloids, recurrent infections, dyspareunia, and dysmenorrhea. Neuromata and infertility are seen, but are rare. Decreased sexual responsiveness, psychological sequelae, or even posttraumatic stress syndrome, are understandably common.

Aesthetic procedures in the genital area can resemble female cutting in terms of technique and final result, but the fundamental difference lies in the intention and the purpose never to harm the functionality of the female genitals with this surgery. ${ }^{9,15}$

Obviously, patients should be aware that this surgery carries inherent risks and complications that eventually can result in a diminished function. ${ }^{3}$

For plastic surgeons performing aesthetic genital surgery, four ethical principles mark the difference with genital cutting practices ${ }^{11}$ :

1. Autonomy of the patient: Patients should be over 18 years old, psychologically stable, and fully informed on the risks and expected results, so that the decision in full knowledge of the issue is theirs only. An informed consent should always be obtained.

2. Nonmaleficence: The "first of all to do no harm" principle of Hippocrates specifically applies in genital surgery, which should never result in genital or sexual dysfunction.

3. Beneficence: Literally this means "to do good," which translates to performing high-quality surgery, promoting good health. It also means that the surgeon is ethically obliged to train himself in this field and have enough expertise to perform the best possible surgery.

4. Justice: This principle applies to the greater good of society. A purely aesthetic correction should not be performed at the expense of others and the surgeon should not try to obtain financial coverage by social security or national health care systems if this is not provided.

If any of these preconditions is not fulfilled, aesthetic genital surgery should not take place. ${ }^{15}$

Furthermore, a surgeon is not obliged to perform the surgery if he has ethical or principle objections. The indication for surgery is made in a mutual understanding: A one-sided decision made by the patient or the surgeon is to be avoided. There are no absolute medical contraindications for aesthetic genital surgery, although current gynecological disease, smoking, unrealistic expectations, and sexual dysfunction are relative contraindications. ${ }^{1,6}$

It is worthwhile mentioning here that, similar to many other plastic surgery interventions, there is not always a strict separation between aesthetic and reconstructive genital surgery. Probably in the majority of patients, the indication is partially reconstructive (for a functional or medical indication) as well as aesthetic (for cosmetic reasons). This is illustrated by M. Goodman who attempted to pull genital surgery out of the dark with his proposal for indications and guidelines. ${ }^{16}$

Indications:

1. Perceived genital hypertrophy or significant discrepancy

2. Discomfort with sports activities or clothing, or vaginal entrapment with coitus

3. Genital changes due to childbearing or obstetrical injury affecting beauty or gripability and pleasurable coital sensation.

\section{LABIOPLASTY}

Labioplasty refers to reduction of the labia minora (mostly) or majora, as well as to augmentation through injection of bulking agents or autologous fat transfer. ${ }^{1}$

The function of the labia minora is to protect the vagina from drying out and the labia play a significant role in the process of micturition by funneling the urine stream, therefore the minimal labial width should be $1 \mathrm{~cm} .{ }^{2,13}$

\section{Reduction of Labia Minora}

Reduction labioplasty has been reported in the peerreviewed medical literature since 1971 .

As discussed earlier, there are surprisingly few descriptions of normal female genitalia in the medical literature, with variations in the dimensions of the labia minora from $7 \mathrm{~mm}$ up to $5 \mathrm{~cm} .{ }^{5}$ Generally, the labia are considered as hypertrophic if the maximum distance from the base to edge is greater than $5 \mathrm{~cm}^{5,16,17}$

Hormonal changes during puberty result in growth of the external genitals in such a way that the inner labia mostly become "longer" than the outer labia. Therefore, some women interpret the results of these physiological changes as abnormal and might feel insecure about the shape of their external genitals. Because shaving of the pubic hair is a growing custom nowadays, women are more and more confronted with their protruding inner labia (Fig. 2). ${ }^{18}$

Women will seek labioplasty for different reasons. ${ }^{4,16,17,19}$ Functional indications include: discomfort in clothing or during sports, dyspareunia due to invagination of the labia on penetration can be another functional reason but a growing number of women seek this kind of surgery purely for aesthetic reasons.

Sometimes, a history of sexual abuse may be a reason to request labia reduction. Some women are convinced that when the inner labia are "changed," a new sexual partner will not notice about their earlier abuse. Unfortunately, vulvar surgery might be a trigger 


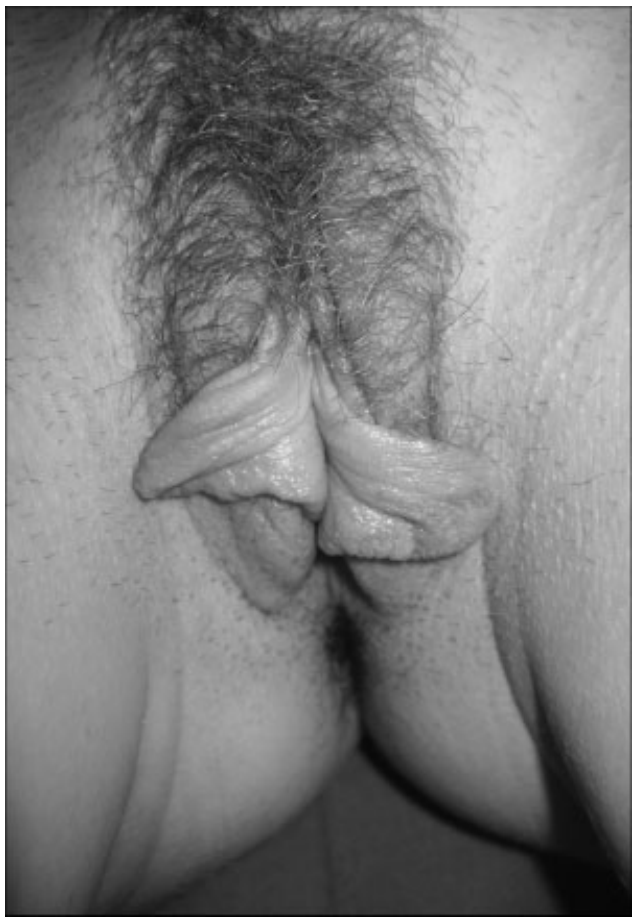

Figure 2 Protruding labia minora.

for repressed memories and can act as a repetition of their earlier trauma. ${ }^{4,18}$

Rouzier et al reported in 2000 on 163 women who received a labia reduction surgery. The primary reason for patients requesting labia reduction surgery was aesthetic dissatisfaction in $87 \%$ of cases, discomfort in clothing in 64\%, and dyspareunia by invagination of the protuberant tissue in $43 \% .{ }^{19}$

The vulvar epithelium of labia minora is highly innervated and sensitive. During sexual arousal, the labia evert and contribute to erotic sensation and pleasure. Incision to any part of the genitalia could compromise this sensitivity and its sexual importance. Neuroma-like hypersensitivity has been reported after surgery. $5,8,13$

Many techniques have been described and some will be discussed in detail here.

\section{LABIAL AMPUTATION OR EDGE EXCISION TECHNIQUE}

This technique was the first one described and is the simplest one: a complete excision of the excess labial tissue over its entire length is performed; the edges are then sutured together with absorbable sutures, usually in a running technique (Fig. 3). The major disadvantage of this technique is that it removes the natural contour of the free edge of the labium minus.

Sometimes, the inner lining of the labia becomes everted and the pink color becomes visible giving the labia an unnatural appearance.

When performing an amputation one must keep in mind to limit the amputation level to a minimal width of at least $1 \mathrm{~cm}$. Amputations performed with a smaller
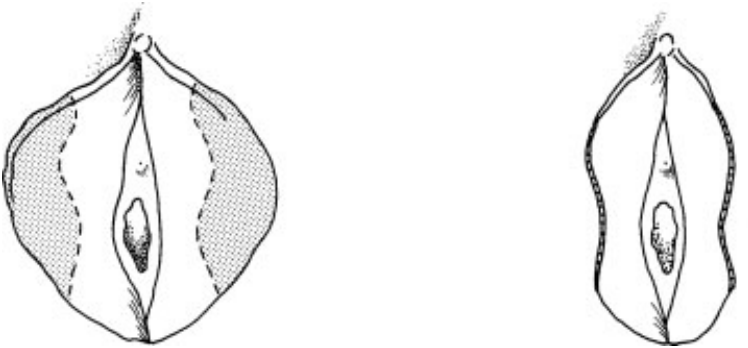

Figure 3 Amputation of the labia minora (edge excision technique).

minimal width can result in unaesthetic scarring too close to the introitus (Fig. 4) causing dyspareunia, sensory loss, or chronic pain. ${ }^{2,13}$

Amputation of the labia is rarely indicated and could be an acceptable surgical procedure in excessively large labia where a simple, purely functional procedure is required especially in elderly patients or when the vascularization of the flap is compromised because of associated disease.

\section{DE-EPITHELIALIZATION TECHNIQUE}

Choi proposed to simply de-epithelialize a central part on both sides of the labia without touching the labial vessels or nerves, and then reapproximate the edges of the defect on both sides the labia (Fig. 5). Although this technique preserves sensitivity of the free border and reduces the vertical dimension, it fails to (substantially)

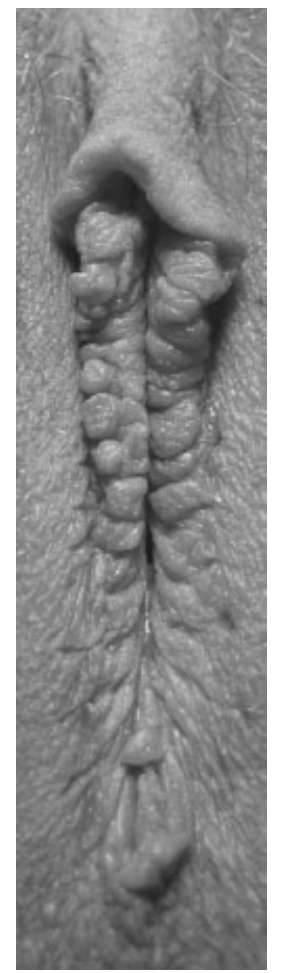

Figure 4 Overresection of the labia minora with unfavorable scar formation. 


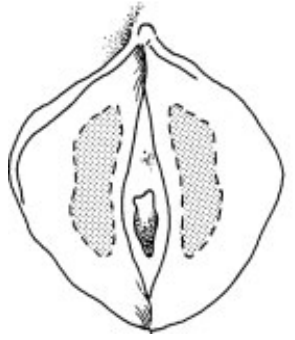

Figure 5 De-epithelialization technique.

shorten the length of the free border, which can appear redundant. Other disadvantages include the increased labial thickness (retained central parenchyma) and abrupt color change at the suture line. $7,13,18$

Patients with the least amount of hypertrophy are reported to be most effectively treated with the deepithelialization technique.

\section{WEDGE RESECTION LABIOPLASTY}

This technique was first described by Dr. Alter and consists of a full thickness wedge excision centrally or at the posterior part of the labia minora which has the advantage of making the residual scar almost completely invisible (Fig. 6, 7). It preserves the natural outline, the pigmentation of the free edge and the neurovascularity,
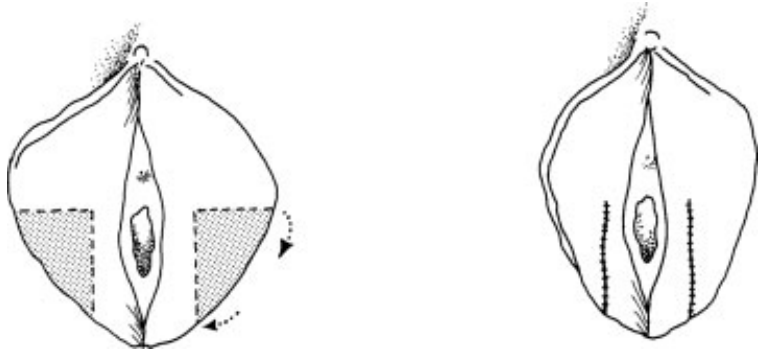

Figure 6 Reduction of the labia majora by wedge excision.

although there is a potential sensory loss at the top of the labium. $7,9,18$

When performing a central wedge resection it is useful to first draw the resection line and then infiltrate underneath the external skin as well as the internal mucosal layer so that the three layers of the labia minora become apparent. The resection of the outer and inner lining is then done in an oblique way to preserve as much of the subcutaneous layer as possible because it almost always retracts. Perfect hemostasis is very important here since a hematoma will result in traction on the suture lines with a risk of wound dehiscence, asymmetry of the labia, and/or suboptimal aesthetic outcomes. Meticulous suturing of the subcutaneous layer is important to prevent wound dehiscence and fistula formation. ${ }^{13,20}$
A
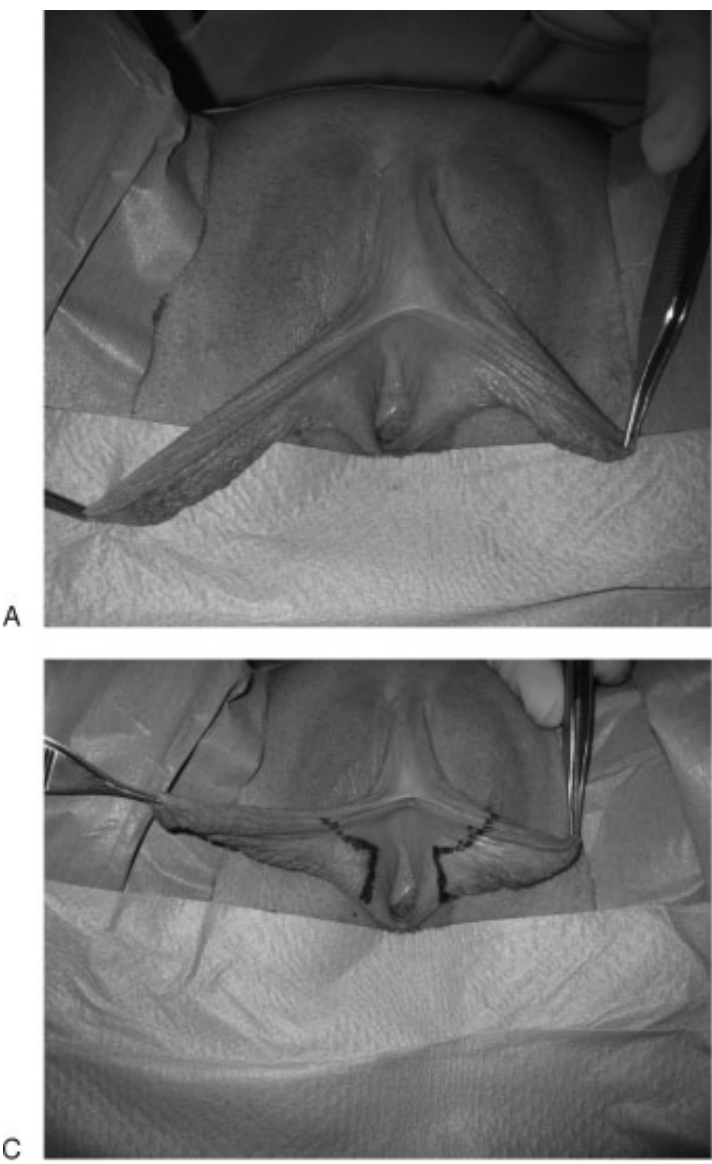
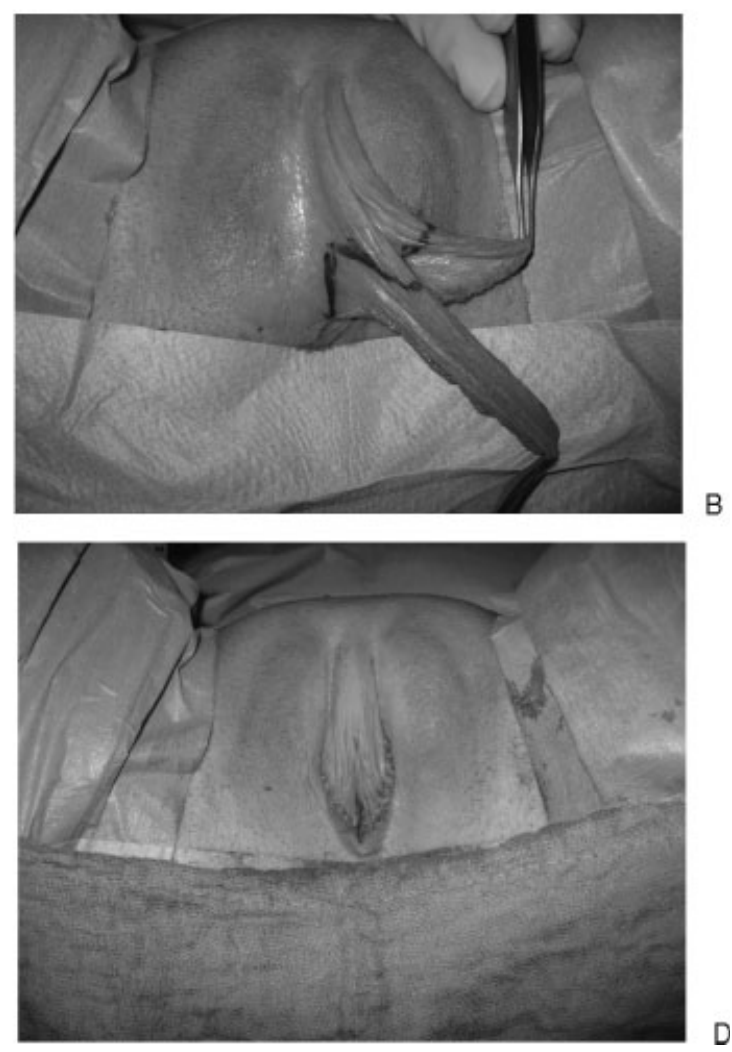

Figure 7 Wedge resection labioplasty. (A-D) Preoperative views. 

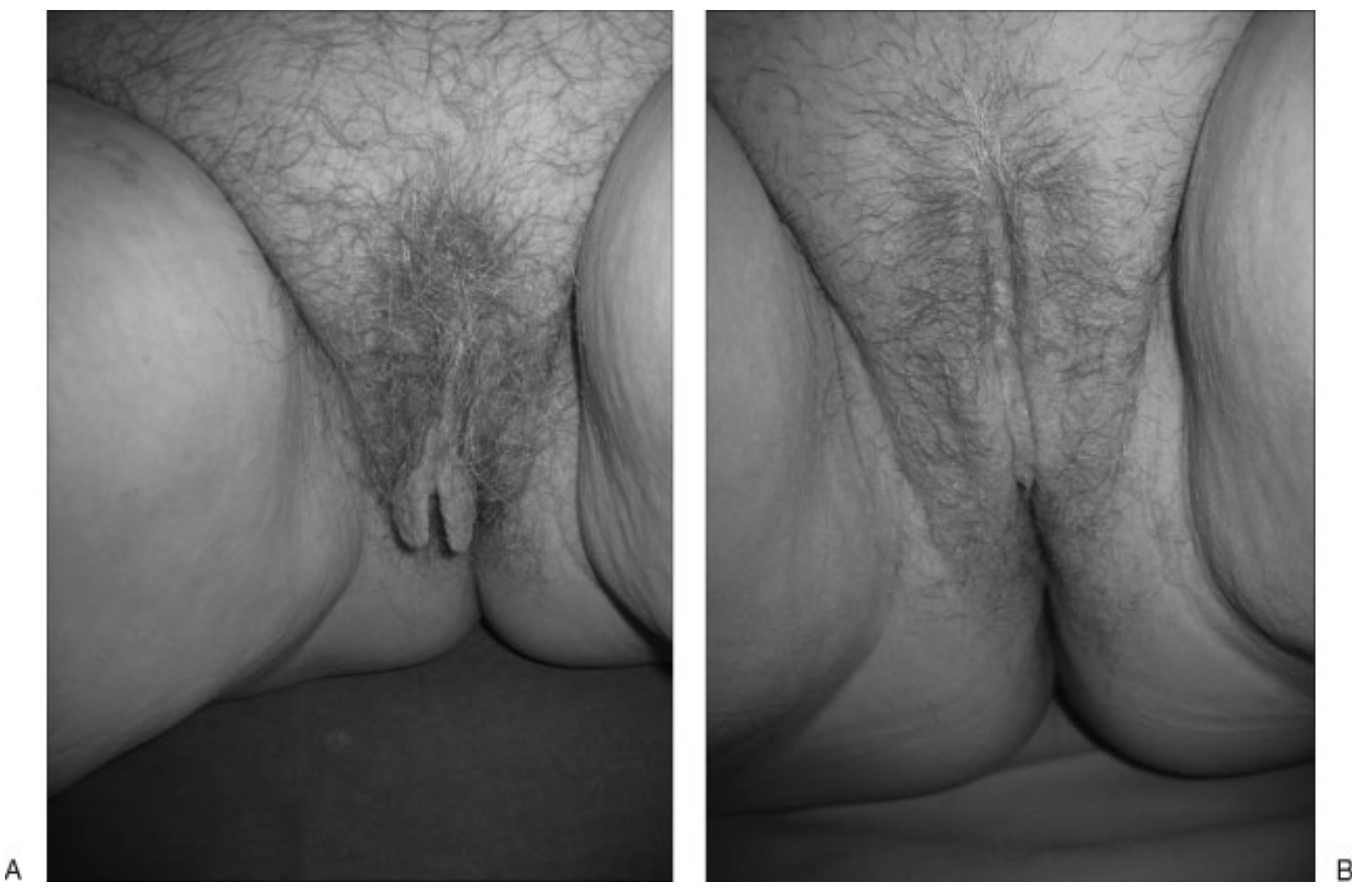

Figure 8 Wedge resection labioplasty. (A) preoperatively; (B) late postoperative result.

To avoid traction on the suture line, Giraldo et al proposed a 90 -degree Z-plasty to spread the tension more equally spread over the suture line.

Another technique is the inferior wedge resection technique by Munhoz in 2006. The wedge is taken in the inferior part of the labia, using the superior large remnant as a flap to reconstruct the labia. ${ }^{20}$

Care should be taken not to extend the labial resection to the fourchette and to keep the labial width to $\sim 1 \mathrm{~cm}$, so that the labia will protrude just past the introitus (Fig. 7). ${ }^{13}$ Some swelling immediately postoperatively is to be expected and the first postoperative visit is usually scheduled around 1 week. Sooner in case of swelling, pain, or hematoma. Normally, patients can return to work after only 3-4 days. Sexual intercourse, bicycling, and intensive sports should be stopped for 4-6 weeks, until complete healing of the wounds has occurred.

Long-term consequences of labial surgery have not yet been examined. There have been some rare reports of unpleasing aesthetic results after surgery and even secondary dyspareunia. ${ }^{18}$

In conclusion, the wedge resection is the technique of choice: It preserves neurovascularity and the natural color of the labial edge and it shortens labial length as well as labial width.

\section{Reduction of Labia Majora}

When speaking of redundant labia majora, a difference should be made between primary labia majora hypertrophy (volume excess) and secondary labia majora hypertrophy due to volume loss (skin excess). When there is a true volume excess, the enlarged labia majora can be reduced by liposuction. However, this might create sagging and skin excess. In case of skin excess due to volume loss, a reduction of the labia majora can be performed using a longitudinal wedge excision of the excess tissue with the incision along the length of the labia minora (Fig. 8). ${ }^{21}$ Postoperative complications of a wedge excision are bleeding and transient hypersensitivity for 4 to 6 weeks. ${ }^{16}$

\section{Augmentation Labioplasty}

Literature is very scarce on augmentation labioplasty. The procedure is mostly done in the labia majora and consists of augmentation through autologous fat injections or lipofilling. Fat can be harvested from the abdomen or the inner thigh. ${ }^{21}$ When performing a lipofilling of the labia majora a rather minor hypertrophy of the smaller labia can be masked. In case of a substantial labia minora hypertrophy, a reduction labioplasty can be performed with lipofilling of the labia majora.

\section{VAGINAL TIGHTENING PROCEDURE}

During life, up to $76 \%$ of women experience decreased vaginal sensation, most commonly with a feeling of a widened vagina. What exactly is decreased vaginal sensation? Schultz et al investigated vaginal sensitivity in a group of 60 volunteers by means of an electric stimulus under nonerotic conditions. In comparison to 
the dorsum of the hand, the vagina had a low sensitivity in general with no evidence of decreased sensitivity when directly stimulated. They conclude that the decreased vaginal sensation must come from a widened vagina, causing less friction. ${ }^{22}$

Vaginal laxity, as it is called, is a common complaint among parous women. ${ }^{23}$ Although women report that reduced sexual sensation is the most common specific symptom of vaginal laxity, it is not clear that this phenomenon is directly related to sexual dysfunction. ${ }^{1,9}$

Vaginal tightening surgery has been around since the mid fifties, where gynecologists used to tighten the entrance of a woman's vagina with an extra stitch while repairing vaginal and perineum tears or episiotomies after giving birth. At that time it was notoriously known as the "husband's stitch," the "husband's knot," or the "vaginal tuck," and doctors discreetly referred to this procedure as "improving a woman's well-being."”

The goal of these procedures is to reconstruct (or to narrow) the lower third of the vagina, which includes "the orgasmic platform, internal and external vaginal diameter (introitus) and the perineal body." ${ }^{24}$ The procedure enhances vaginal muscle tone strength and control, and decreases internal and external vaginal diameters. Women choosing to have their vaginas tightened are generally healthy women without true functional disorders. ${ }^{3}$ In vaginal tightening procedures, portions of mucosa are excised from the vaginal fornices (via scalpel, needle electrode, or laser) to surgically "tighten" the lower third of the vagina. Presently there is no standardization of this procedure: It can be an anterior colporrhaphy, a high-posterior colporrhaphy, an excision of lateral vaginal mucosa, or a combination. ${ }^{1}$

In most cases, a mucosa strip is simply excised and primarily closed with an absorbable running suture. Several studies suggest the lateral colporrhaphy (Fig. 9) to be a more effective technique in reducing the size of the vagina without placing scars within the areas of highest sensitivity, thereby causing less dyspareunia.
Known complications are localized infection and vaginal bleeding. Ninety five percent of patients treated with lateral colporrhaphy reported an improvement in sexual sensitivity, as well as greater vaginal tightness at the 6 months follow-up. ${ }^{1,3,9,23}$

More recently, there have been several reports on vaginal tightening through injection of autologous fat or bulking agents such as hyaluronic acid. ${ }^{25}$ Hyaluronic acid is never a definite solution, it resorbs over time, and multiple injections can be necessary to maintain the wanted result. With lipofilling, mention has been made of a possible effect on mucosal trophicity in postmenopausal women, but also on the risk of partial resorption and even granuloma formation.

Up to now, there are no large studies and no long-term results known, so this technique is to be regarded as still experimental. Although we know from our experience in penile girth and glandular augmentation that these techniques are relatively safe to use.

It is not possible at the moment to predict how long the results of vaginal tightening procedures will last, and it may be safe to assume that the results will not be permanent, as with any rejuvenating procedure. Implications of cosmetic mucosal vaginal tightening for $\mathrm{pa}^{-}$ tients planning to have children after the procedure are not known. ${ }^{9,23}$

\section{HYMENOPLASTY}

The hymen is the mucous membrane that partially closes the entrance to the vagina, named after the god of marriage in classical Greek mythology, Hymenaios.

The hymen serves no known biological function in adults, and its rupture is of no medical consequence; therefore, its repair has no direct medical benefit. ${ }^{26}$ The absence of hymen is not a sign of lost virginity; and same is true for bleeding on first night. ${ }^{27}$ A recent study revealed that hymen was intact in as many as $52 \%$ of adolescent girls who admitted to have had sexual intercourse. The hymen is a relatively bloodless membrane
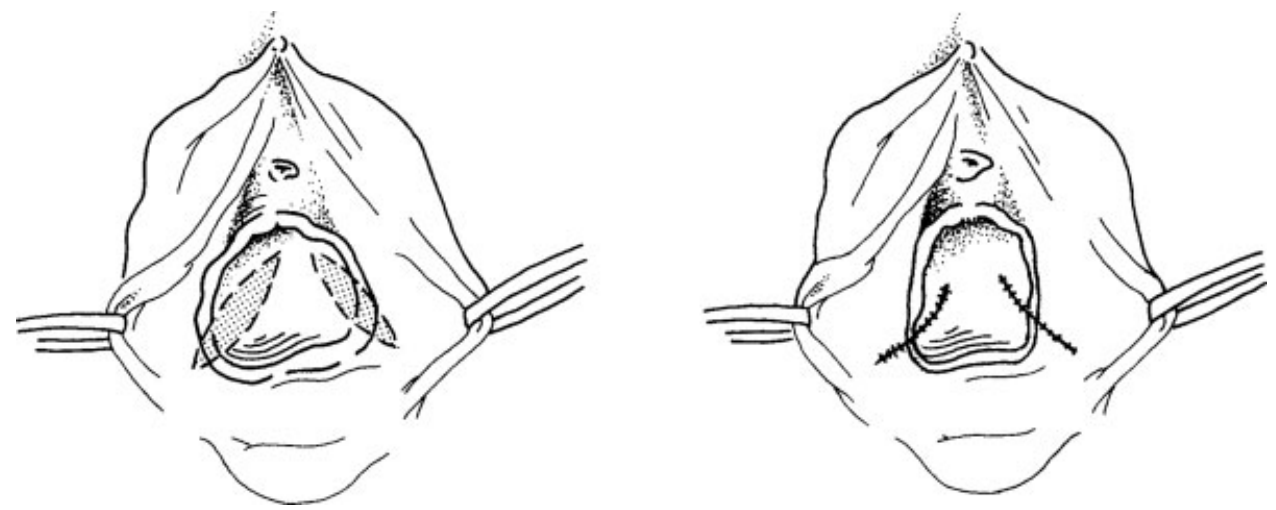

Figure 9 Vaginal tightening through lateral colporrhaphy. 
and it is unlikely to bleed significantly even if it is torn. Violent penile penetration can result in minor laceration of the vaginal wall that appears to be responsible for "blood-stained bedsheets." Therefore, promoting the concept of intact hymen as a sign of virginity is nothing but perpetuation of myth. ${ }^{26}$

Unfortunately, in some cultures, the status has become emblematic of family honor and worth and young women sometimes go to great lengths to get their hymen repaired.

A
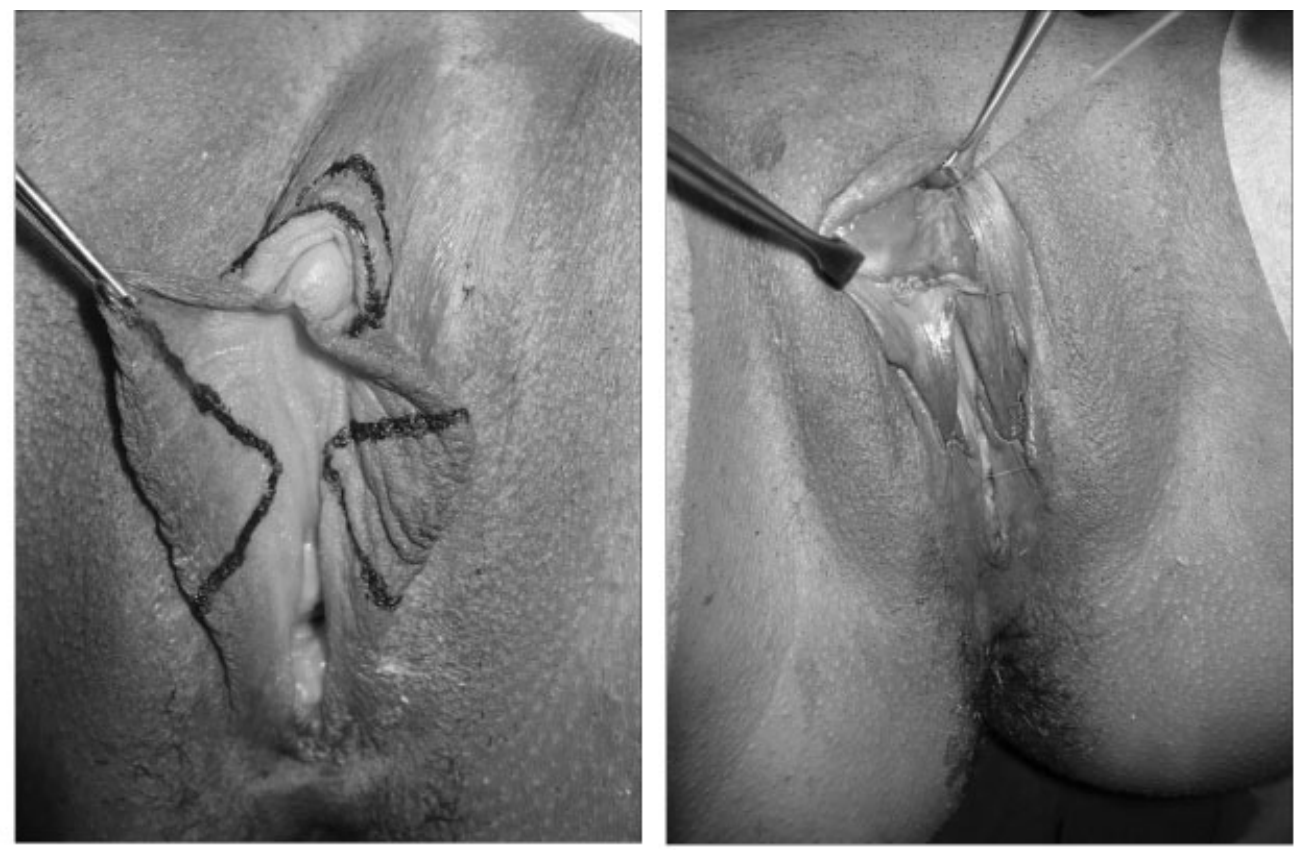

Against this background, a request for repair of the hymen, whether ruptured in intercourse or not, is not necessarily a purely cosmetic choice analogous to breast enlargement and liposuction. It may serve purposes more worthy and protective than personal vanity.

An objection based on human rights is that the procedure perpetuates discrimination against women in the expectation of virginity in unmarried women not expected or required of unmarried men. On the

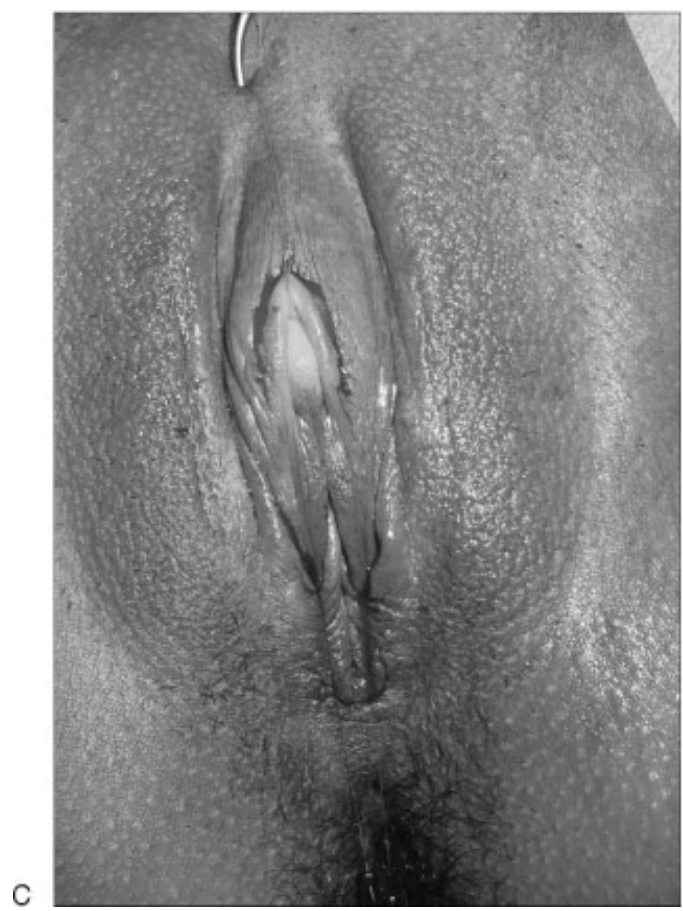

Figure 10 Clitoral hood reduction (in this case performed together with a central wedge nymphectomy and clitoropexy). (A) Demarcation for both wedge numphectomy and clitoral hood reduction. (B) Dissection of the clitoral hood to the root of the clitoris and clitoropexy. (C) Resection of redundant skin of the clitoral hood. 
other hand, there is the argument in feminist advocacy that any decision made by a competent woman regarding her own body and medical treatment should be respected. ${ }^{27,28}$

The hymenoplasty procedure consists of surgically tailoring the hymenal remnants so that they can be sutured together with absorbable interrupted sutures to narrow the vaginal orifice. ${ }^{27}$ The procedure can be repeated as many times as desired. We found no data on whether the hymen is more likely to bleed when the reconstruction has been done a longer time in advance. ${ }^{9}$ Follow-up is usually scarce because the procedure itself serves a short-lived purpose and the patient often wishes to stay anonymous.

Another delicate matter concerning hymenoplasty is monetary coverage. Should there be partial monetary coverage in those cases where the surgery is not performed for aesthetic reasons?

\section{CLITOROPLASTY}

The clitoris is the embryonic equivalent of the male penis and is packed with 8000 nerve endings, twice the number of its male counterparts. ${ }^{29,32}$

A clitoris that is too large or is given the chance to grow too long through maturity is regarded as socially or medically abnormal, making a woman too masculine, and thus, (hetero)sexually strange and unattractive.

\section{Clitoral Hood Reduction}

Clitoral hood reduction is designed to produce more exposure of the clitoral body (with theoretically improved sexual stimulation) and to improve the appearance of the genital area.

Clitoral hood reductions are usually performed via simple skin excision, using lateral preputial or a central croissant-formed excision. Excisions should never be done longitudinally on the midline because of possible scarring and subsequent dysfunction.

A lateral clitoral hood reduction can be combined with a wedge excision labioplasty, where the wedge can be prolonged along the clitoral hood (Fig. 10). The resection line should never come close to the border of the clitoris because scars close to the clitoris can result in sexual dysfunctioning.

Women request revision of their clitoral hoods usually for two reasons. Occasionally, the clitoris is "buried" under an overabundant prepuce, or "trapped" under a tight, phimosed hood, leading to little direct stimulation, regardless of maneuvers attempted. Second, as with hypertrophied labia, many women find their generous preputial folds unsightly and a source of embarrassment (although rarely do their sexual partners find this to be a problem). ${ }^{1,17,21}$

\section{Clitoropexy}

Clitorises viewed to be longer than usual and deemed to look more like a penis than a clitoris must be reduced to ensure social acceptance as a female. ${ }^{3}$

Clitoropexy consists of a $\mathrm{V}$-to-Y plasty, moving the clitoris and its attached labia minora in an anterior and superior direction. A deep holding suture from the suspensory ligament of the clitoris to fascia or periosteum of the pubis is helpful. ${ }^{13}$ This should be made at the medial and the lateral side of the clitoris and never in the midline where the neurovascular pedicle is located (Fig. 10). ${ }^{8}$

\section{Clitoral Reduction}

Clitoral hypertrophy may be primary or secondary to hormonal or genetic abnormalities such as in disorders of sex development (DSD).

Clitoral reduction differs from clitoropexy in that it truly reduces the length of the clitoral shaft or/and head, with preservation of sensitivity. Correction of a clitoral hypertrophy is often more a reconstructive functional procedure rather than a purely cosmetic procedure.

\section{PERINEOPLASTY}

Perineoplasty involves surgical reconstruction of the vaginal introitus, usually with a minor low-posterior compartment repair and reapproximation of the levator ani musculature.

A diamond-shaped wedge of tissue is removed, with the apex in the posterior lower one third of the vagina and the nadir on the perineum superior to the anus. The "wings" of the diamond extend laterally

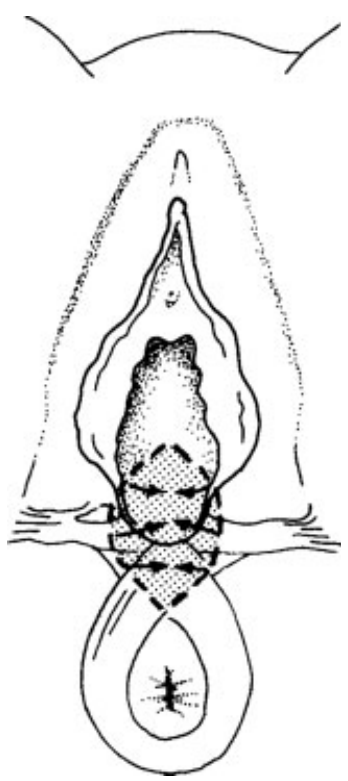

Figure 11 Perineoplasty by excision of a diamond wedge. 
to the hymeneal ring. Reapproximation of the levator muscles causes an elevated perineum and a strengthened perineal body resulting in an improved sexual function (Fig. 11). ${ }^{1,17}$ Complications are superficial hypersensitivity and vaginal or perineal constriction. In the majority of the cases, this can be resolved by perineal stretching and vaginal dilators. ${ }^{17}$

\section{PUBIC ENHANCEMENT}

\section{Pubic Lifting}

Reduction of the mons pubis for ptosis and excess tissue in this area usually requires direct wedge excision in a transverse direction. This procedure is usually combined with or part of an abdominoplasty procedure (Fig. 12). ${ }^{21}$

\section{Pubic Liposuction}

Liposuction of the mons pubis is effective in patients without skin excess.

If the patient is undergoing an abdominoplasty, wedge resection of the fat pad through the lower abdominal incision is effective. ${ }^{21}$

\section{G SPOT AMPLIFICATION}

The $G$ spot or Gräfenberg spot was first described in the 1950s as a highly erogenous zone inside the vagina that enlarges when directly stimulated. The erotic zone can be found on the anterior wall of the vagina along the course of the urethra, which seems to be surrounded by erectile tissue much like the corpora cavernosa of the penis. Although the location varies, the $G$ spot is typically located about half way between the pubic bone and the cervix, $\sim 2$ to $5 \mathrm{~cm}$ into the vagina. ${ }^{29,30}$ Recently, the King's College London published an article in the Journal of Sexual Medicine involving 1800 women between 23 and 83 years old, and found no proof of the existence of the $\mathrm{G}$ spot. $^{31}$

As a counterattack, an Italian group published an article saying that they could locate the G spot using ultrasound scans. ${ }^{31}$

The quest for the G spot still remains: To be or not to be?

G spot amplification was first described by Matlock in $2001 .^{33}$ The procedure is mostly focused on a functional improvement: It is believed to enhance the sexual stimulation to the $G$ spot through increased projection of the $\mathrm{G}$-spot into the vagina $(3-5 \mathrm{~mm})$. In a nonaugmented state, the G-spot lays beneath the surface of the vaginal wall and needs to be stimulated indirectly, when projected into the vagina the $G$ spot is more accessible for stimulation.

The amplification is performed by collagen or hyaluronan injections under local anesthetic. It is an office procedure where the patient first indicates the right zone to be augmented by palpation. The effect of the current bulking agents is not permanent because of
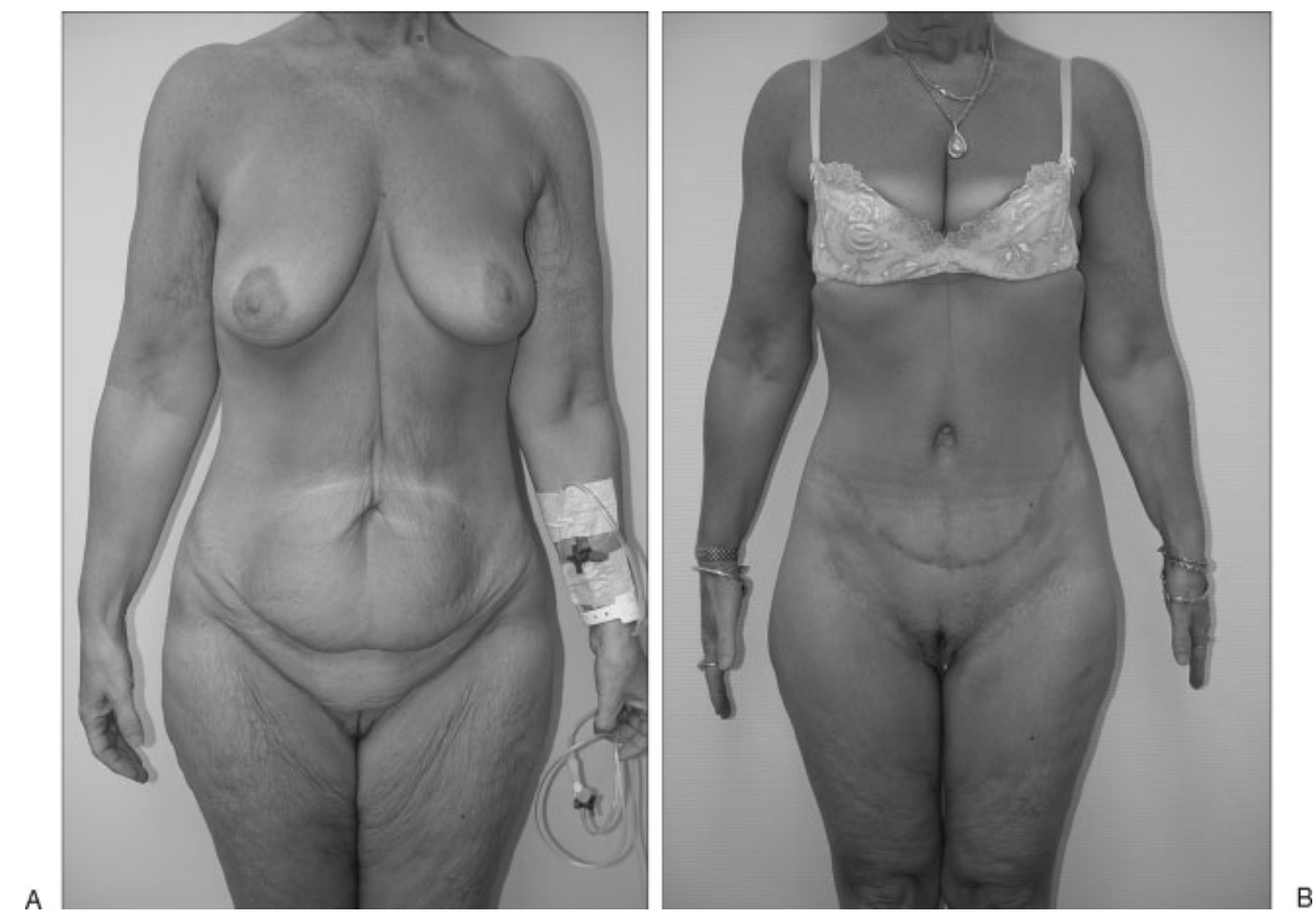

Figure 12 Pubic lifting in combination with an abdominoplasty procedure: (A) preoperatively; (B) postoperative result. 
resorption; it usually lasts for 6 to 9 months. The big advantage of this temporary effect is that exposurehypersensitivity through injections can be undone simply by waiting.

In Matlock's pilot study, up to $87 \%$ of women undergoing $\mathrm{G}$ spot amplification surveyed an enhanced sexual arousal.

When discussing the risks, we must keep in mind that there are no long-term studies available for $\mathrm{G}$ spot amplification, and that functionality can be harmed. Known complications are hypersensitivity, urinary infection, urinary retention, urethral irritation, periurethral pseudocyst formation, urethrovaginal fistulas, postoperative bleeding, and erosion of the $\mathrm{G}$ spot with open sores and scars.

\section{CONCLUSION}

Female genital surgery mostly consists of a labioplasty or a vaginal tightening procedure. These surgical procedures seem to have acceptable complications and a reasonable cosmetic outcome.

In 2009, M. Goodman et al published a crosssectional study, including 258 women and 12 surgeons, of 104 labioplasties, 24 clitoral hood reductions, 49 combined labioplasty/clitoral hood reductions, 47 vaginoplasties and/or perineoplasties, and 34 combined labioplasty and/or reduction of the clitoral hood plus vaginoplasty/perineoplasty procedures. The procedures were studied retrospectively, analyzing both patient's and physician's perception of surgical rationale, preoperative sexual function, and several outcome criteria.

Combining the three groups, $91.6 \%$ of patients were satisfied with the results of their surgery after a 6to 42-month follow-up. Significant subjective enhancement in sexual functioning for both women and their sexual partners was noted $(P=.0078)$, especially in patients undergoing vaginal tightening or perineal support procedures. Complications were acceptable and not of major consequence. ${ }^{17}$

There is an urgent need for guidelines in indications and a standardization of procedures. Long-term follow up studies will be necessary to evaluate the outcome of genital aesthetic surgery.

\section{REFERENCES}

1. Goodman MP. Female cosmetic genital surgery. Obstet Gynecol 2009;113(1):154-159

2. Scholten E. Female genital cosmetic surgery-the future. J Plast Reconstr Aesthet Surg 2009;62(3):290-291

3. Green F. From clitoridectomies to 'designer vaginas': The medical construction of heteronormative female bodies and sexuality through female genital cutting. Sexualities Evolution and Gender 2005;7(2):153-187
4. Weijenborg P. 'Designer vaginas'. Een Issue voor sexuologen? Tijdschrift voor Sexuologie 2006;30:181-186

5. Lloyd J, Crouch NS, Minto CL, Liao LM, Creighton SM. Female genital appearance: "normality" unfolds. BJOG 2005; 112(5):643-646

6. Davison S, West J. Labiaplasty and labia minora reduction. Available at: http://emedicine.medscape.com/article/1372175overview. Accessed Feb. 8, 2010

7. Giraldo F, González C, de Haro F. Central wedge nymphectomy with a 90-degree Z-plasty for aesthetic reduction of the labia minora. Plast Reconstr Surg 2004; 113(6):1820-1825; discussion 1826-1827

8. Mei Lia L, Creighton S. Requests for cosmetic genitoplasty: how should healthcare providers respond? Demand for cosmetic genitoplasty is increasing BMJ 2007;334:1090-1092

9. Cartwright R, Cardozo L. Cosmetic vulvovaginal surgery. Obstetrics, Gynaecol Reprod Med 2008;18(10):285-286

10. Essén B, Johnsdotter S. Female genital mutilation in the West: traditional circumcision versus genital cosmetic surgery. Acta Obstet Gynecol Scand 2004;83(7):611-613

11. Goodman MP, Bachmann G, Johnson C, et al. Is elective vulvar plastic surgery ever warranted, and what screening should be conducted preoperatively? J Sex Med 2007;4(2): 269-276

12. Donohoe M. Female genital cutting: epidemiology, consequences and female empowerment as a means of cultural change. Ob/Gyn \& Women's Health 2006;11(2).

13. Choi HY, Kim KT. A new method for aesthetic reduction of labia minora (the deepithelialized reduction of labioplasty). Plast Reconstr Surg 2000;105(1):419-422; discussion 423-424

14. Gruenbaum E. The female circumcision controversy: an anthropological perspective. Philadelphia: University of Pennsylvania Press; 2001

15. Hage J, Karim R, van der Lei B, et al. Grenzen aan de esthetische genitale chirurgie bij vrouwen. Standpunt van de NVPC/ NVOG/ NVEPC 2008. Available at:. http://www. nvpc.n1/stand/10standpunten_25_04_08_01.pdf. Accessed Feb. 8, 2010

16. Di Saia JP. An unusual staged labial rejuvenation. J Sex Med 2008;5(5):1263-1267; discussion 1263-1267

17. Goodman MP, Placik OJ, Benson RH III, et al. A large multicenter outcome study of female genital plastic surgery. J Sex Med 2010;7(4 Pt 1):1565-1577

18. Paarlberg KM, Weijenborg PT. Request for operative reduction of the labia minora; a proposal for a practical guideline for gynecologists. J Psychosom Obstet Gynaecol 2008;29(4):230-234

19. Miklos JR, Moore RD. Labiaplasty of the labia minora: patients' indications for pursuing surgery. J Sex Med 2008; 5(6):1492-1495

20. Munhoz AM, Filassi JR, Ricci MD, et al. Aesthetic labia minora reduction with inferior wedge resection and superior pedicle flap reconstruction. Plast Reconstr Surg 2006;118(5): 1237-1247; discussion 1248-1250

21. Kolb S. Plastikos Surgery Centre, Atlanta. Aesthetic female genital surgery: expanding your practice. Available at:http:// www.labiaplastysurgeon.com/sexual-enhancement.html. Accessed Feb. 8, 2010

22. Schultz W, van de Wiel H, Klatter J, et al. Vaginal sensitivity to electric stimuli: theoretical and practical implications. Arch Sex Behav 1989;18(2):87-95

23. Ciro A, Corvi M. Cosmetic mucosal vaginal tightening (lateral colporrhaphy): improving sexual sensitivity in women 
with a sensation of wide vagina. Plast Reconstr Surg 2009; 123(6):212-213

24. Olliver. Designer vagenas. 2000, Nov 14. Available at http:// dir.salon.com/sec/feature/2000/11/14/vagina/index/html

25. Brambilla M. Intramuscular-submucosal lipostructure for the treatment of vaginal laxity. Paper presented at: Congresso Internazionale di Medicina Estetica; October 10; 2008; Milan, Italy

26. Raveenthiran V. Surgery of the hymen: from myth to modernization. Indian J Surg 2009;71:224-226

27. Prakash V. Hymenoplasty - how to do? Indian J Surg 2009;71: 221-223

28. Cook RJ, Dickens BM. Hymen reconstruction: ethical and legal issues. Int J Gynaecol Obstet 2009;107(3):266-269
29. The Esybron Institute 2007. The female genital system. Available at: http://www.esybron.org/index.phtml?p=female. Accessed May 21, 2010

30. Goldstein I, Meston C, Davis S. Women's sexual function and dysfunction: study diagnosis and treatment. London: Taylor and Francis; 2006

31. Burri AV, Cherkas L, Spector TD. Genetic and environmental influences on self-reported G-spots in women: a twin study. J Sex Med 2010;7(5):1842-1852

32. Gravina GL, Brandetti F, Martini P, et al. Measurement of the thickness of the urethrovaginal space in women with or without vaginal orgasm. J Sex Med 2008;5(3):610-618

33. Physician info, the G-shot: overview. Available at: www. thegshot.com. Accessed May 21, 2010 